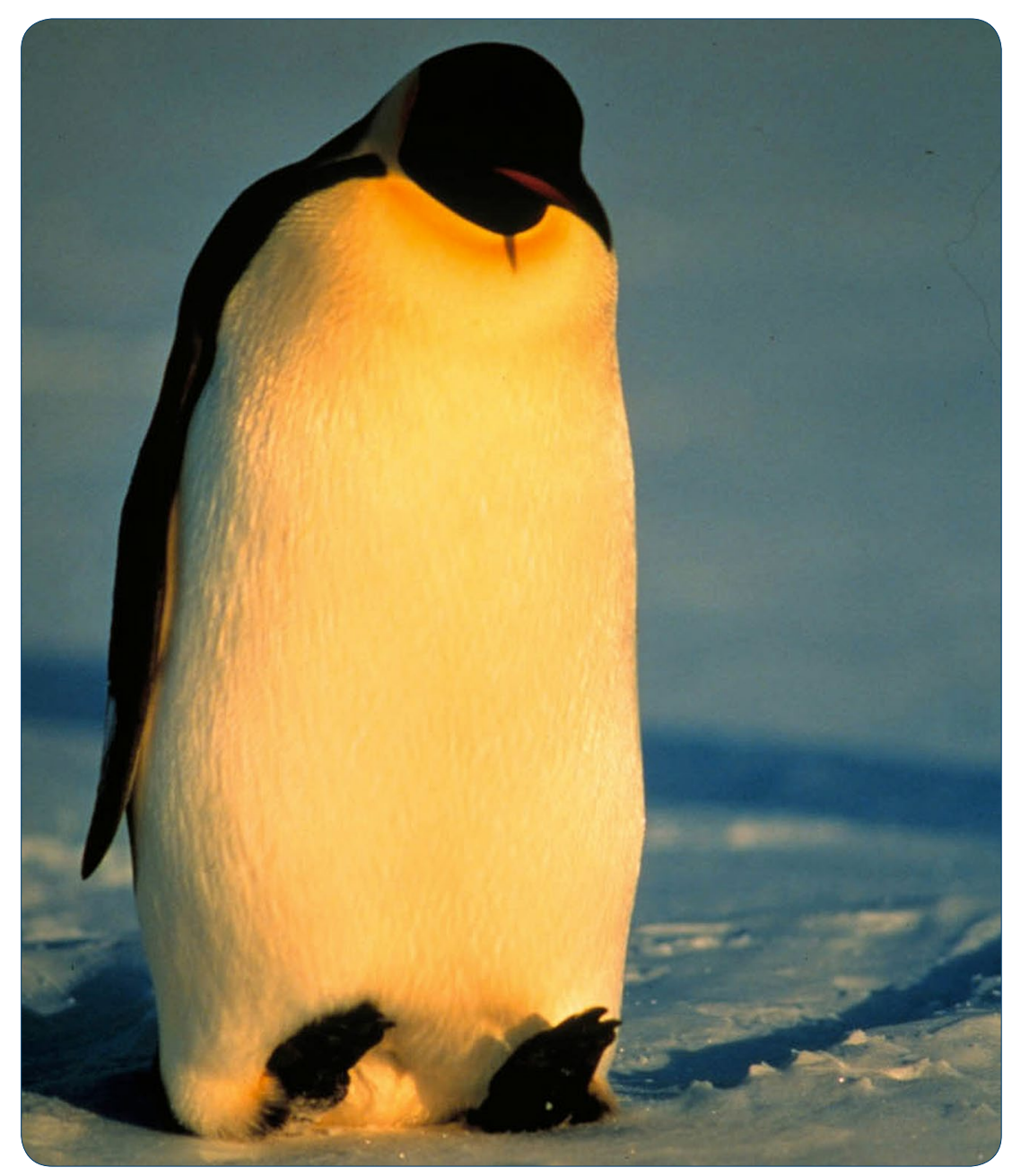

\title{
Why do satellite transmitters on emperor penguins stop transmitting?
}

Kooyman et al. 


\title{
Why do satellite transmitters on emperor penguins stop transmitting?
}

Gerald L. Kooyman ${ }^{1 *}$, Birgitte I. McDonald ${ }^{1,2}$ and Kimberly T. Goetz ${ }^{3,4}$

\begin{abstract}
Background: Investigation of early transmission failure from animal-borne, satellite transmitters should reveal vital information about the reliability of the technology, and the risk of application to the animal. Current technology available to the investigator does not provide firm evidence for causes of transmitter blackout.

Findings: We address the five most likely causes of satellite transmitter failure on 20 adult (10 male and 10 female) emperor penguins tagged near Cape Colbeck, Antarctica, and one near the Drygalski Ice Tongue, Western Ross Sea, during late summer, 2013. They are: 1. Technical failure of the transmitter, 2. Instrument breakage, 3. Instrument loss because of attachment failure, 4. Predation, and 5. Icing of the salt water detection switch. The longest record of 323 days suggests that prior losses were not due to power failure.

Conclusions: Various possibilities of transmission blackout are discussed, and we speculate about the most likely causes of termination of transmissions. A loss of transmission from six tags at similar locations early in the deployments suggests predation. Later losses at random times and locations may be because of antenna breakage or attachment failure. Definite conclusions cannot be made because of the indirect assessment of transmission loss. We suggest some changes in deployment procedures to improve our ability to determine cause of satellite transmission termination in the future. Understanding causes of blackout is important both scientifically and ethically in terms of accurate data interpretation and balancing the benefits of scientific gain with the costs of animal disturbance.
\end{abstract}

Keywords: Splash tag, Spot tag, Satellite transmitters, Blackout, Emperor penguin, Antarctica

\section{Background}

Ever since investigators began attaching satellite tags to emperor penguins, Aptenodytes forsteri, 20 years ago, with no plans for recovery, it has been a test of longevity for the transmitters [1]. Initially, transmitters were deployed on penguins to determine their foraging locations during 1-3 week trips to sea for the purpose of nurturing their chicks, after which they were removed from the bird [2-7]. For long-term experiments on adult penguins, in which the tags were not recovered, there is little speculation or conclusions about the reasons for tag transmission loss. However, data show that losses are high for king penguins, A. patagonicus, traveling in pack ice during the winter $[8,9]$. Most other experiments have

\footnotetext{
*Correspondence: gkooyman@ucsd.edu

${ }^{1}$ Center for Marine Biotechnology and Biomedicine, Scripps Institution

of Oceanography, 9500 Gilman Drive, La Jolla, CA 92093, USA

Full list of author information is available at the end of the article
}

focused on juvenile emperor penguins immediately after fledging, with the hope of tracking them as long as possible through their first year of independence. Since juvenile birds initially lack hunting skills and evasive tactics from predators, losses due to inexperience and starvation and/or predation may have occurred. Surprisingly, a respectable percentage (50-67\%) of these juveniles survived from summer to autumn [10-12]. By that time the birds were well beyond the Antarctic waters, and with the changing condition of ice free waters, a new set of challenges for both foraging and predator avoidance come into play and the studies are not comparable to the results of this report.

Long-term tracking studies are relatively common for sea turtles resulting in a report on why the satellite tags stop transmitting [13]. Hays et al. [13] suggested four reasons for transmission loss: 1. Battery power depletion, 2. salt water switch (SWS) interruption by bio-fouling, 3. detachment of the transmitter, and 4. death of the 
turtle. They concluded that fouling of the SWS was the most common cause of tag failure (8 of 14 tag failures), but battery depletion ( 2 failures) and antenna damage (1 failure) were also responsible for some of the tag failures. They were unable to determine the cause of failure for three turtles.

Here we report on the study of 21 adult emperor penguins that were tracked after their molt. This was challenging because molt areas are usually remote from any research station. In fact, in this case they represent one of the most distant locations of concentrated wildlife on the planet. Different from the fledgling studies of emperor penguins, these birds were robust, $25-35 \mathrm{~kg}$ adults with years of foraging and predator avoidance experience. We used the newest model Splash tags (2012) with current advances in battery technology. Our expectations were that the tracking would last well into the winter if not beyond. Instead, many stopped transmitting by midautumn. Using the diagnostic data transmitted from our satellite tags, we investigate the potential causes of termination of satellite transmissions. Additionally, we review past long-term tracking studies, and combine this information with our findings to speculate on the reasons for early termination of satellite transmissions.

\section{Methods}

\section{Field methods}

Twenty-one emperor penguins were captured in the Ross Sea, Antarctica during a research cruise aboard the R/V Nathanial B. Palmer in March 2013. Penguins were sighted from the bridge of the ship and approached by foot, snowmobile or small boat depending on ice conditions. One penguin (P1) was captured in the pack ice in the Western Ross Sea (WRS) $\left(75^{\circ} 37^{\prime} \mathrm{S}, 167^{\circ} 56^{\prime} \mathrm{E}\right)$ on February 24 th. The remaining 20 penguins were captured within the vicinity of Cape Colbeck ( $\left.77^{\circ} 04^{\prime} \mathrm{S}, 157^{\circ} 49^{\prime} \mathrm{W}\right)$, in the Eastern Ross Sea (ERS), between March 14 and 17.

All attachments were completed using procedures similar to a previous protocol [14], with the exception that the tags were prepared before deployment with a flat black coating of paint and a nose taper glued to the front of the tag (Fig. 1). In brief, a penguin was hooked with a shepherds crook, quickly hugged, and then hooded. A second person secured a harness around the torso and with a third person used a suspension scale for weighing. Mass was determined to the nearest $0.5 \mathrm{~kg}$ using a Pesola $50 \mathrm{~kg}$ spring scale.

\section{Attachment and tag type}

The tag was attached immediately following weighing, following a strict, stepwise protocol as follows: 1. A stiff platform of feathers was created using a small amount of Loctite 401 on the dorsal mid back, 2. after the glue

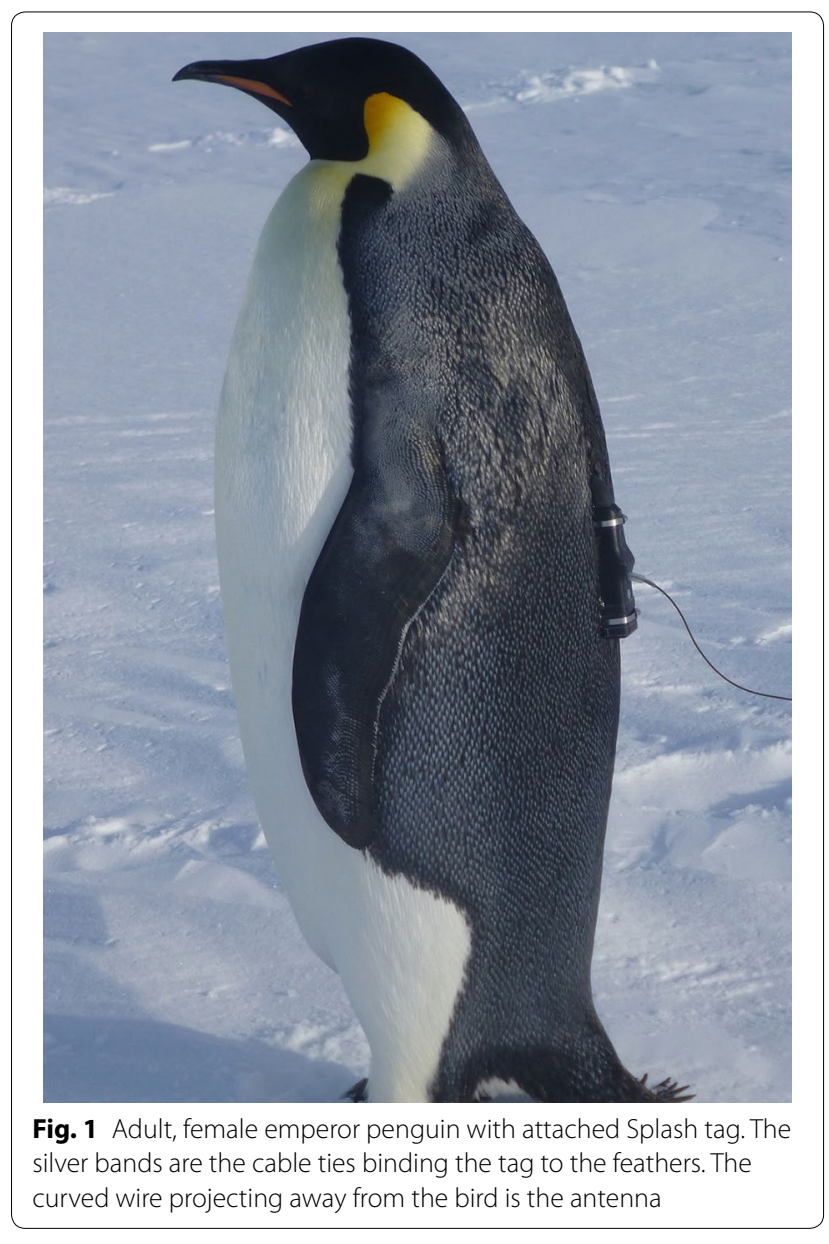

set $(<1 \mathrm{~min})$, two stainless steel cable ties were placed under the feather platform, 3. a thin layer of 5 min epoxy (Loctite; Henkel Corp., Westlake, OH, USA) was placed on the bottom of the tag, and 4. the tag was anchored to the penguin by tightening the cable tie loops with a Panduit cable tie gun set to a predetermined tightness level. After approximately $10 \mathrm{~min}$, when the glue was set, a few contour feathers were collected from each bird to determine gender. The samples were sent to Dr. Tom Hart for analysis (Department of Zoology, University of Oxford, South Parks Road, Oxford, OX1 3PS, UK). The analysis was based on Han et al. [15]. Then the bird was released. Each bird was photographed as it moved away. The whole procedure took approximately $15 \mathrm{~min}$. Sixteen Splash [model: Splash10-283B, $109 \times 32 \times 26 \mathrm{~mm}(L \times$ $W \times H$ ), $99 \mathrm{~g}$ ] and five Spot five tags, (model: Spot-293A, $72 \times 54 \times 24 \mathrm{~mm}, 119 \mathrm{~g}$, Wildlife computers, Redmond, WA, USA) were deployed. All procedures were approved under the UCSD Animal Subjects Committee Protocol (S10113) and US Antarctic Treaty Permit (2013-006).

Both Splash and Spot tags were duty cycled to transmit every third hour $(0,3,6,9,12,15,18$, and $21 \mathrm{~h})$ of 
every day at which times the tag would transmit every $\sim 45 \mathrm{~s}$ when at sea and $\sim 90 \mathrm{~s}$ when dry. Transmissions were paused if dry for more than 9 and $12 \mathrm{~h}$ for splash and spot tags, respectively. However, Splash tags would still attempt to transmit every eighth day during this time. When a unit was in water again, transmissions resumed. Maximum transmissions per day were 200 for Spot or 250 for Splash tags. Tags periodically transmitted tag diagnostic data including battery voltage and number of transmissions.

\section{Results}

All penguins were adults with body masses ranging from 22 (recent post-molt) to $37 \mathrm{~kg}$. Additional file 1: Table S1 summarizes details for each bird. The longest lasting tag, in terms of number of transmissions, was penguin 15 (P15). This tag transmitted 52,483 times in 290 days. The last diagnostic voltage transmitted by the tag was over $3 \mathrm{~V}$, which is nominal for function. P15 transmissions ended in the pack ice northeast of Cape Colbeck (Fig. 2). The longest functional duration was P3 with the last transmission after 323 days. It shut down at Cape Colbeck.

Most of the tags did not transmit for as long as the above transmitters, or as long as predicted by battery capacity. For example, 11 transmitters deployed near Cape Colbeck went offline within 68 days of deployment, when battery failure should not have been an issue (Additional file 1: Table S1). Five tags (P2, 8, 9, 10, 12) stopped transmitting near the Bay of Whales (BofW) (Fig. 2). Two others, P5 and P18, were north of BofW and P21 was near Cape Colbeck. The location of the last transmissions from the remaining three tags was widely scattered (P4, $6,7)$. They all stopped transmitting in the pack ice north of BofW from 30 April to 21 May (Fig. 2). Incidentally, two of the shortest records, P18 and 21, were the two largest birds tagged (Additional file 1: Table S1). End battery voltages from these 11 tags ranged from 2.9 to $3.2 \mathrm{~V}$.

The nine remaining tags deployed on penguins at Cape Colbeck continued to transmit into the winter before tag failure (24 July 2013 to 31 January 2014). The first failure of these tags occurred on 24 July, which exceeded the duration of the previous longest transmitting tag by nearly double. At the time of tag failure, four of the nine emperor penguins $(\mathrm{P} 11,14,15,16)$ were beyond the shelf slope and outside the Ross Sea. P17 was to the northwest of Cape Colbeck and on the shelf slope. In addition, four of the five birds with tags that continued transmitting through winter into the spring (21 September) returned to Cape Colbeck or to the nearby pack ice (P3,13, 15, 20).

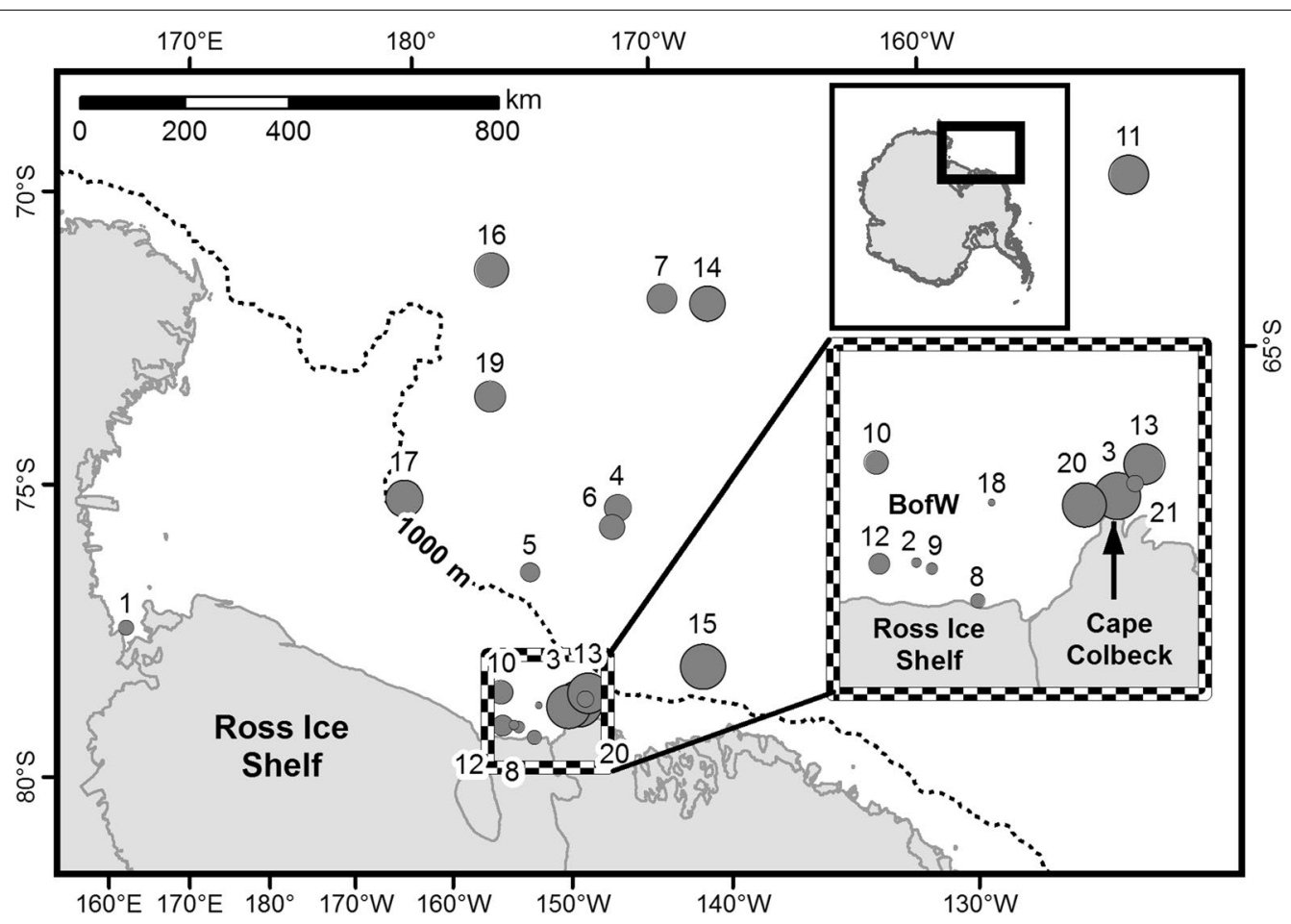

Fig. 2 Locations of the final transmissions from 21 tagged emperor penguins. All animals were originally tagged at Cape Colbeck with the exception of bird 1 which was tagged in the WRS. Symbol size denotes length of tag deployment with larger circles showing longer transmission durations. The $1000 \mathrm{~m}$ contour, or shelf break, is represented by the black dotted line 
A tag from one penguin (P3) transmitted every eighth day while nearly stationary in Bartlett Inlet (location of the Cape Colbeck colony) between 27 October and 31 January 2014, indicating the bird, or transmitter, was out of the water during this time. In contrast, P11 remained in the far northeast until her tag stopped transmitting on 5 October, 205 days after release (Fig. 2).

P1 is not compared to the birds in the ERS because it was tagged far west of all others. She was an early postmolt bird tagged near the Drygalski Ice Tongue. She had traveled for 27 days to McMurdo Sound, about $200 \mathrm{~km}$ south of her original position, where her last location was determined. In all cases, except P3's final months of transmitting every eighth day, transmissions were daily.

During autumn when new ice was forming, emperor penguins probably commonly break through the thin ice to breathe while on the go, or to exit the water. This activity and the risk to the tag are shown well in Fig. 3. It must create much wear on those birds that frequently practice the procedure.

\section{Discussion}

Two major events occurred after capture and release of the ERS birds. In the first event, all 20 birds tagged at or near Cape Colbeck traveled from the tagging location to the area near BofW (tracks not shown). Such consistency seems remarkable, but in agreement with the large number of seals and penguins observed in the area while we were enroute to Cape Colbeck from the WRS. It was first called the Bay of Whales by Ernest Shackleton during his 1907-1909 Nimrod Expedition, because of the large concentration of whales found there. Although most of the whales are gone, a large concentration of seals

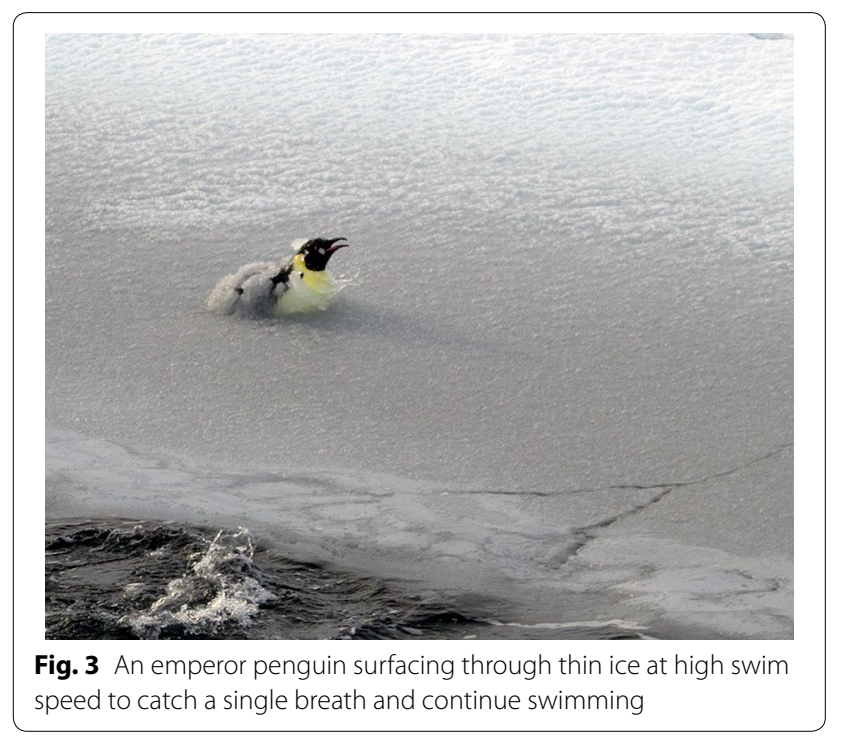

remains [16]. A large concentration of emperor penguins was noted to the east of BofW just before we arrived at Bartlett Inlet (Gearheart, unpublished observations). It seems to be a foraging "hot spot" and, significant for this paper, 6 of the 20 tags stopped transmitting in the vicinity of the BofW after short durations ranging from 12 to 51 days post-deployment (Additional file 1: Table S1). The only shorter duration deployment that we are aware of is the juvenile emperor penguin that was released in open water at about $52 \mathrm{~S}$ latitude [17]. This 4-day deployment on such a robust juvenile emperor penguin may have been a predatory event. Although the environments and experience of the penguins are not comparable, the early transmission termination of the tags on 12 birds ( $<30$ days for 4 of the penguins) in or near BofW suggests predation events. The 12 and 17 days of P15 and P2 are within the duration of many previous deployments of TDR's or satellite transmitters on emperor penguins that were nurturing chicks at their respective colonies around Antarctica (1-4 weeks), or while tracking adults after departure for their pre-molt journey (1-3 months) [3-7]. Under foraging and nurturing circumstances, recovery success of TDR's for birds from the Cape Washington colony was about $91 \%$ (Kooyman, Ponganis unpublished observations) after a trip duration of 1-3 weeks. For the birds on journeys to molt areas, $85 \%$ successfully reached their destination after about 30 days, in some cases over $1000 \mathrm{~km}$ from their departure point $[10,11]$. Consequently, all of the early losses in such a dynamic region around the BofW could have been due to predation.

Another possible reason for transmission loss is tag removal by the penguin. Tag removal can occur directly by: 1 . birds preening their feathers (Kooyman personal observations), and/or 2. scraping off the tag under the ice (Cassondra Williams personal observations). In addition, tag removal can also occur indirectly by: 3 . birds smashing through the ice to breath (Fig. 3), especially during March and April when new ice is forming (a condition which is possibly unique to this species), and 4. ice buildup on the tag [18]. All of these activities could have crippled the tag by breaking the antenna, the most vulnerable part of the tag and critical for data transmission. Finally, 5. the ice formation could have disabled the SWS, but there was no indication of periodic tag shut down. All transmitted daily for the tag duration. Consequently, determination of early transmission termination of tags that failed after 68 days at sea in regions other than the BofW is problematic. While the likelihood of predation is possible, wear and tear of feathers on the tag becomes more likely. Deterioration of tag attachment and the tag itself (antennae, battery life) is cumulative. Tags may have been damaged by the ice and/or fallen off due to the breakdown of feathers at the attachment site. 
Anecdotal evidence such as under-ice scraping of the back mounted tag has been observed to occur by emperor penguins swimming under ice. At the "Penguin Ranch" (a purpose built enclosure for the penguins, which included an under-ice observation chamber and diving hole through which the penguins could forage) in McMurdo Sound during previous studies birds that were wearing instrument packs were seen scraping the rough under-ice bottom as if trying remove the pack (C. Williams personal observations). Also, observed at the Ranch during October of 2000, where emperor penguins were retained in an outdoor corral, was that ice formed within a day and accumulated on the attached recording devices over a period of several days [18]. Even if total removal of the device is unsuccessful, transmission loss could be due to antenna breakage. This seems most likely if the birds were scraping under the ice, or smashing through thin ice. Of course, the longer the bird is at sea the greater the chance of damaging the attachment and of leopard seal predation. The chance of predation would be enhanced further if the tag acted as a target. We tried to reduce the visibility of the tag as described in the methods, and there would be the additional liability of a different stroke frequency and swim speed of the encumbered birds from that of other emperor penguins.

Many of the tags on emperor penguins that transmitted into the winter (P19) to 323 days (P3), failed well to the north near or beyond the Ross Sea shelf slope. This is an area of high productivity and one where their diet probably changes dramatically from Antarctic silver fish to krill and mid-water deep dwelling lantern fish [19]. By this time there would have been substantial wear on the tags, especially from any birds prone to attempting to dislodge the tags, or surfacing through thin ice. Air temperatures are much lower at this time with shorter days and waning solar input, and ice accumulation on the tag could be an important consequence. During a dive, the tag temperature equilibrates to the water temperature, approximately $-1.85{ }^{\circ} \mathrm{C}$. After the animal exits the water, the tag is exposed to much lower air temperatures and the water adhering to the tag may freeze, forming a skin of ice that can accumulate on successive dives, unless some force breaks it off [18]. More bulk would be added to the tag increasing its drag and greater potential for impact damage any time the bird broke through the ice to breath. Although ice fouling would seem to affect the SWS there was no such apparent susceptibility to the tag. If the SWS was fouled then after 8 days the transmitters should have sent a signal for a day. Such an event occurred only with P3, the longest lasting of all birds. Finally, the battery condition appeared nominal at the last transmission of all transmitters, and the number of transmissions was well within the limits of all transmitters (Additional file 1: Table S1).
The five tags that continued to transmit until spring suggest that much of the loss was the result of stochastic events that are impossible to determine without some designed signal. The final conclusion for this period is that some birds may have torn the tag off, broken the antenna, or died by predation. Unlike with the long-term tracks of juveniles, where starvation may have played an important role in the demise of some birds [8], none of our cohort of birds was likely to have starved. At tagging these were robust adult, experienced birds, and they should have fallen into the $80+\%$ survival group that has been observed in the recent past [20]. Because battery voltage was $>3 \mathrm{~V}$, our best assumption is that there were instrument losses by damage or detachment. The duration of the five tags ranged from 220 (P13) to 323 days (P3), which incidentally is the longest tracking record for any emperor penguin. In the two cases of P3 and P15, the most likely outcome was that the tags fell off at molt.

In summary, we do not know why any of the tags failed, although we suspect the shortest transmission durations were most likely due to predation. That is why we ask the question "why do satellite transmitters on emperor penguins stop transmitting". Some causes of loss may be possible to determine with proper detectors incorporated into the tag. Even resolution of a few of the losses would be an important step forward in learning about emperor penguins on long-term travel studies. At present there is a large investment of time and money into a bird with little possibility of resolving the final outcome. Perhaps a low cost, and much smaller transmitter could be attached concurrently in some way to avoid the risk of under-ice scraping that may be affecting the primary tag. This double coverage would strengthen any indirect evidence of tag loss. For example, if the main transmitter is lost and the second transmitter reception continues, then predation did not occur, thus eliminating one of the main suspects in our case for early loss. The fact remains that some way of knowing or reducing the number of possibilities of transmission loss will enhance the value of tracking studies greatly.

\section{Additional file}

Additional file 1: Table S1. Summary of tag deployment and performance. Individual ID numbers and mass are provided for each bird. Penguin 1F was tagged in the eastern Ross Sea, and is considered separate from the rest of the penguins tagged near Cape Colbeck. M and $\mathrm{F}=$ male and female, BofW = Bay of Whales, $\mathrm{AS}=$ Amundsen Sea and tx $=$ transmission.

Abbreviations

ERS: Eastern Ross Sea; WRS: Western Ross Sea; BofW: Bay of Whales. 


\section{Authors' contributions}

All co-authors participated in designing and writing the manuscript. All participated in conducting the field work. KG collected the data from the satellite transmissions and analyzed the data. All authors have read and approved the final manuscript.

\section{Author details}

${ }^{1}$ Center for Marine Biotechnology and Biomedicine, Scripps Institution of Oceanography, 9500 Gilman Drive, La Jolla, CA 92093, USA. ${ }^{2}$ Moss Landing Marine Laboratories, 8272 Moss Landing Road, Moss Landing, CA 95039, USA. ${ }^{3}$ Department of Ecology and Evolutionary Biology, University of California Santa Cruz, 100 Shaffer Road, Santa Cruz, CA 95060, USA. ${ }^{4}$ National Institute of Water and Atmospheric Research Ltd, 301 Evans Bay Parade, Wellington 6021, New Zealand.

\section{Acknowledgements}

Supported by NSF ANT 1043454. We thank Chief Scientist Dennis Hansell for all his help and smooth running of the Tracer program, and Geoffrey Gearheart as a member of our team with many operational suggestions and restraining the birds during the attachment of the transmitters. The safe boat operations by the marine technicians, and onboard operations by the crew of the Icebreaker Nathaniel B. Palmer made it happen. Of course, we are grateful to Captain Sebastian Paoni for taking us all over the Ross Sea, and then to the remotest corner of the Ross Sea, and getting us back to South America as autumn and new ice were advancing. Last but not least all the volunteers who helped manage the emperor penguins during the deployments. BIM was supported by a NSF international fellowship (IRFP 1159123) during analysis and writing of the paper.

\section{Competing interests}

The authors declare that they have no competing interests.

Received: 30 April 2015 Accepted: 20 October 2015

Published online: 02 November 2015

\section{References}

1. Kooyman GL, Kooyman TG, Horning M, Kooyman CA. Penguin dispersal after fledging. Nature. 1996;383:397.

2. Ancel A, Kooyman G, Ponganis PJ, Gendner PJ, Lignon JP, Mestre J, Huin $X$, Thorson PH, Robisson P, Maho YL. Foraging behaviour of emperor penguins as a resource detector in winter and summer. Nature. 1992;360:336-9.

3. Kirkwood R, Robertson G. Seasonal change in the foraging ecology of emperor penguins on the Mawson Coast, Antarctica. Mar Ecol Prog Ser. 1997; 156:205-23.

4. Kirkwood R, Robertson G. The foraging ecology of female emperor penguins in winter. Ecol Monogr. 1997;67:155-76.
5. Kooyman GL, Kooyman TG. Diving behavior of emperor penguins nurturing chicks at Coulman Island, Antarctica. Condor. 1995;97:536-49.

6. Wienecke BC, Robertson G. Foraging space of emperor penguins Aptenodytes forsteri in Antarctic shelf waters in winter. Mar Ecol Prog Ser. 1997;159:249-63.

7. Zimmer I, Wilson RP, Gilbert C, Beaulieu M, Ancel A, Ploetz J. Foraging movements of emperor penguins at Pointe Géologie, Antarctica. Polar Biol. 2008;31:229-43.

8. Bost CA, Charrassin JB, Clerquin Y, Ropert-Coudert Y, Le Maho Y. Exploitation of distant marginal ice zones by king penguins during winter. Mar Ecol Prog Ser. 2004;283:293-7.

9. Moore GJ, Wienecke B, Robertson G. Seasonal change in foraging areas and dive depths of breeding king penguins at Heard Island. Polar Biol. 1999;21:376-84.

10. Kooyman GL, Ponganis PJ. The initial journey of juvenile emperor penguins. Aquat Conserv: Mar Freshwr Ecosyst. 2007;17:S37-43.

11. Wienecke B, Raymond B, Robertson G. Maiden journey of fledgling emperor penguins from the Mawson Coast, East Antarctica. Mar Ecol Prog Ser. 2010;410:269-82.

12. Thiebot J-B, Lescroel A, Barbraud C, Bost C-A. Three-dimensional use of marine habitats by juvenile emperor penguins Aptenodytes forsteri during post-natal dispersal. Antarct Sci. 2013;25:536-44.

13. Hays $G$, Bradshaw C, James M, Lovell P, Sims D. Why do Argos satellite tags deployed on marine animals stop transmitting? J Exp Mar Biol Ecol. 2007;349:52-60

14. Kooyman G, Hunke E, Ackley S, van Dam R, Robertson G. Moult of the emperor penguin: travel, location, and habitat selection. Mar Ecol Prog Ser. 2000;204:269-77.

15. Han J-I, Kim J-H, Kim S, Park S-R, Na K-J. A simple and improved DNA test for avian sex determination. Auk. 2009;126:779-83.

16. Ackley S, Bengtson J, Boveng P, Castellini M, Daly K, Jacobs S, Kooyman G, Laake J, Quetin L, Ross R, Siniff DB, Stewart BS, Stirling I, Torres J, Yochem PK. A top-down, multidisciplinary study of the structure and function of the pack-ice ecosystem in the eastern Ross Sea, Antarctica. Polar Record. 2003;39:219-30.

17. Miskelly CM, Simpson PM, Argilla LS, Cockrem JF. Discovery, rehabilitation, and post-release monitoring of a vagrant emperor penguin (Aptenodytes forsteri). Notornis. 2012;59:116-22.

18. Kooyman GL, Ponganis PJ: The icing of external recorders during the polar winter. In: Naito Y, editor. Memoirs of National Insitiute of Polar Research, Special Issue, No 58, 15-22, 2004 BIO-LOGGING SCIENCE; 2004; Tokyo, Japan; National institute of polar research; 2003.

19. Kooyman GL, Siniff DB, Stirling I, Bengtson JL. Moult habitat, pre- and post-moult diet and post-moult travel of Ross Sea emperor penguins. Mar Ecol Prog Ser. 2004;267:281-90.

20. Barbraud C, Weimerskirch $\mathrm{H}$. Emperor penguins and climate change. Nature. 2001;411:183-6.

\section{Submit your next manuscript to BioMed Central and take full advantage of:}

- Convenient online submission

- Thorough peer review

- No space constraints or color figure charges

- Immediate publication on acceptance

- Inclusion in PubMed, CAS, Scopus and Google Scholar

- Research which is freely available for redistribution 